\title{
Clinical Outcome Comparing Poly-L-lactic acid (PLLA) Bioabsorbable Interference Screws and Cortical Button-Post Fixation in Arthroscopic Anterior Cruciate Ligament Reconstruction
}

\author{
CLAUDIU DANIEL CHITEA ${ }^{1}$, ALINA DIA TRAMBITAS MIRON ${ }^{2 *}$, \\ GHEORGHE TOMOAIA ${ }^{3}$, CRISTIAN TRAMBITAS ${ }^{4}$ \\ ${ }^{1}$ University of Medicine and Pharmacy Cluj-Napoca, 8 Victor Babes Str., 400012, Cluj Napoca, Romania \\ ${ }^{2}$ University of Medicine, Pharmacy, Sciences and Techonology of Targu Mures, Department of Medical Informatics and \\ Biostatistics, 38 Gheorghe Marinescu Str., 540139, Targu Mures, Romania \\ ${ }^{3}$ University of Medicine and Pharmacy, Department of Orthopaedics and Traumatology, 8 Victor Babes Str., 400012, Cluj \\ Napoca, Romania \\ ${ }^{4}$ University of Medicine, Pharmacy, Sciences and Techonology of Targu Mures, Department of Anatomy, 38 Gheorghe \\ Marinescu Str., 540139, Targu Mures, Romania
}

\begin{abstract}
A good fixation for anterior cruciate ligament reconstruction with hamstring tendons graft is important to withstand the stress on the graft resulting from post-operative rehabilitation. The optimal hamstring tendons graft fixation method remains uncertain within the sports medicine literature. The most used fixation techniques include: suspensory fixation with cortical-buttons, transfemoral fixation with cross-pins, and tunnel aperture fixation with interference screws. Patient recruitment and baseline data collection of this study were done at our hospital between July 2011March 2016. In this study we included the records of 80 patients with an ACL rupture who elected to undergo ACL reconstructive surgery with allograft tissue. In our study the patients were mixed in 2 groups: (A) patients with interference bone screw group used for anterior ligament reconstruction graft fixation in both the femur and tibia and (B) patients with the cortical flip button group underwent graft fixation with the button on the femoral side and an interference screw on the tibial side. Our clinical study shows no significant differences in the patients' outcomes after using these two fixation devices.
\end{abstract}

Keywords: ACL reconstruction, interference screw, cortical button

\section{Introduction}

Hamstring tendon (HT) autograft is a very common graft choice for anterior cruciate ligament (ACL) reconstruction [1-4]. A possible problem with using HT is that the soft tissue can take up to 12 weeks to heal within the osseous tunnel [4]. A good fixation is important to withstand the stress on the graft resulting from post-operative rehabilitation [4]. The optimal HT reconstruction fixation method remains uncertain within the sports medicine literature. The most used fixation techniques include: suspensory fixation with cortical-buttons (CB), transfemoral fixation with cross-pins (CP), and tunnel aperture fixation with interference screws (IS) [5]. Biomechanical studies have found various results with this fixation methods [6-10].

In anterior cruciate ligament reconstruction, a stable graft fixation and preparation techniques are essential to avoid graft degradation and failure before biological graft integration. The tibial fixation represents the weakest point of fixation in the early postoperative phase because of the inferior quality of bone at the tibial metaphysis in comparison with the femur [11]. Many surgeons use bioabsorbable aperture interference screw and/or cortical button. The bioabsorbable devices market is growing and the research is ongoing for the ideal bioabsorbable material that provides the best desired function with

*email: miron_alina_dia@yahoo.fr 
no adverse reactions. Interference screws have been widely used for tibial graft fixation. Poly-L-lactic acid (PLLA) is currently being used due to some of its special properties like high biodegradability in biomedical area. However, some modifications in biocompatibility and mechanical properties are sometimes necessary for obtaining better results. Many researchers worldwide have tried to obtain better properties of this polymer composites with inorganic materials for tissue repairing, for example, composites of HA have been used clinically in various forms, such as spheres, films, or scaffolds.

The fixation strength is highly dependent on the screw insertion angle and bone mineral density [11-12]. In comparison with cortical button fixation, lower ultimate failure loads have been reported for tendon grafts that use interference screw fixation, as a result of graft slippage at the screw-tendon bone interface $[6,8,13]$

The purpose of our study was to compare clinical results after ACL reconstruction with HT using suspensory cortical button versus screw fixation.

\section{Materials and methods}

Patient recruitment and baseline data collection of this study were done at our hospital between July 2011- March 2016. In this study we included the records of 80 patients with an ACL rupture who elected to undergo ACL reconstructive surgery with allograft tissue. A team of 2 surgeons performed arthroscopically the ACL reconstructions with HT graft using the anatomical reconstruction. The femoral tunnel was drilled over a guide wire, which was placed through the anteromedial portal. The tibial tunnel was also drilled over a guide wire, which was placed with a tibial drill guide. Femoral fixation was with cortical button or with interference screw and tibial fixation with interference screw. We used a screw with 30\% biphasic calcium and 70\% Poly-L/D-lactide composition.

The including criteria in the study were: the primary ACL reconstruction, absence of cartilage lesions, absence of indication to meniscal suture. All the patients presented before intervention knee instability, positive Lachman, drawer test, Pivot shift, positive MRI. The gender distribution was malefemale 3-1, the average age was 32 years (range 18-45), left knee was involved in 35 cases, right knee in 45 cases, all patients suffered the rupture during sport activities. The patients were divided into two groups: one with interference screw fixation and the second one with cortical button for the femoral tunnel. The two groups followed the same rehabilitation program. Weight bearing was allowed as tolerated next day after surgery. Crutch-assisted walking with range of motion (ROM) limited was allowed for the first 2 weeks. After 4 weeks the ROM was increased up to $90^{\circ}$ with constant increasing every week. Muscular training included quadriceps, hamstrings, and core stability exercise in each stage. Jogging was started at 4 months, when the muscular power had recovered to greater than $65 \%$ of that of the uninjured leg. Cutting and other preinjury athletic activities were resumed gradually after 5 months. Return to sports was allowed after 6 months.

The clinical evaluation was performed at 6 and 12 months. The patients have been evaluated using the Lysholm Knee Scoring Scale, International Knee Documentation Committee score and Pivot Shift Test preoperatively and at 6 and 12 months postoperatively.

\section{Results and discussions}

In our study the patients were mixed in 2 groups: (A) patients with interference bone screw group used for anterior ligament reconstruction graft fixation in both the femur and tibia and (B) patients with the cortical flip button group underwent graft fixation with the button on the femoral side and an interference screw on the tibial side (Table 1). No intraoperative complications occurred. No infections or other complications occurred at any of the patients.

Both groups showed significant improvement in the International Knee Documentation Committee score and the Lysholm Knee Scoring Scale. However, no significant difference in the postoperative functional outcomes was found between the 2 groups (Table 2). No significant difference in stability tests was found between the 2 groups (Table 3 ). 
Table 1. Patients characteristic

\begin{tabular}{|c|c|c|}
\hline & Screw group & Button group \\
\hline Patients & 40 & 40 \\
\hline Age & $20-45(32)$ & $18-45(31)$ \\
\hline Sex & 28 males & 32 males \\
\hline Partial meniscectomy & 12 females & 8 females \\
\hline
\end{tabular}

From our knowledge the patient included in this study have not underwent to ACL revision until the present date.

One of the most important information shown by our study is that there was no significant difference between the two groups. The comparison of knee stability, functional outcomes, or incidence of revision procedures between these two technics of graft fixation seems to be similar. These findings suggest that graft fixation method should be decided based on surgeon preference and experience.

Table 2. Functional scores

\begin{tabular}{|c|c|c|c|c|c|}
\hline & \multicolumn{2}{|c|}{ Group A } & & \multicolumn{2}{c|}{ Group B } \\
\hline & Preop. & $\begin{array}{c}\text { Postop. 6/12 } \\
\text { months }\end{array}$ & & Preop. & $\begin{array}{c}\text { Postop. } \\
6 / 12 \\
\text { months }\end{array}$ \\
\hline IKDC & $22-35$ & $88-94 / 92-98$ & & $21-34$ & $\begin{array}{c}90- \\
95 / 92-95\end{array}$ \\
\hline LYSHOLM & $50-58$ & $86-90 / 86-92$ & & $54-58$ & $\begin{array}{c}88- \\
92 / 88-93\end{array}$ \\
\hline
\end{tabular}

Table 3. Functional outcome

\begin{tabular}{|c|c|c|c|c|c|}
\hline & \multicolumn{2}{|c|}{ Group A } & \multicolumn{2}{c|}{ Group B } \\
\hline Pivot shift & Preop. & $\begin{array}{c}\text { Postop. 6/12 } \\
\text { months }\end{array}$ & Preop. & $\begin{array}{c}\text { Postop. } \\
6 / 12 \\
\text { months }\end{array}$ \\
\hline Negative & 0 & 38 & 0 & 37 \\
\hline Grade I & 10 & 2 & 12 & 3 \\
\hline Grade II & 19 & 0 & 16 & 0 \\
\hline Grade III & 11 & 0 & & 12 \\
\hline
\end{tabular}

Although the result shows no important differentiations between these two possibilities of graft fixation, we must have knowledge of some characteristics of these devices and the possible complication that they can cause.

One of the most discussed phenomena after reconstruction of the anterior cruciate ligament with autologous tendon grafts is bone tunnel widening. Although the long-term outcome of this phenomenon is not yet known, tunnel expansion may be clinically relevant in revision surgery because the enlarged tunnels may complicate graft placement and fixation [14,15]. In cases with excessive tunnel enlargement, preoperative bone grafting may be necessary [15]. One mechanism for primary tunnel enlargement is tunnel dilation by the screw $[14,16]$.

There are theoretical advantages of both techniques. With the interference screws fixation results a shorter total length of the graft construct, which increases stiffness of the knee, in theory, in case of 
button fixation, the elastic modulus of the graft is assumed to be constant over its length, due to mitigation of the "bungee cord" effect $[17,18]$.

Button fixation has theoretical advantages. In the laboratory, it has been shown that the tibial and femoral insertions of the ACL cover a substantial surface area, or "footprint," [19-23] which may be reproduced to better using suspensory fixation. In contrast, the footprint area is compromised during screw fixation because the screws themselves fill much of the footprint, displacing graft collagen. This results in less anatomic restoration of the footprint [24].

In the literature, there are some complications reported when using screw fixation for tibial tunnel: local bony lyses, cyst formation, soft tissue inflammation and release of implant fragments into the joint space [25-27]. It is known that the biomaterials degradation is affected by many factors like material composition, biochemical properties and patient factors, such as age, site of implantation, rate of blood flow and stress on the implant. This makes it difficult to identify the cause of adverse effects [31,32] with the implants and inspire us to find better and more biocompatible implants [28-32].

\section{Conclusions}

Our clinical study shows no significant differences in the patients' outcomes after comparing ACL allograft reconstruction using aperture fixation and ACL allograft reconstruction using suspensory fixation. Also, every patient must be treated individually taking care of the level of activity performed and the type of the sport activity.

\section{References}

1.GIANOTTI SM, MARSHALL SW, HUME PA, BUNT L., Incidence of anterior cruciate ligament injury and other knee ligament injuries: a national population-based study, J Sci Med Sport. 2009;12: 622-627.

2.BENCARDINO J, BELTRAN J, FELDMAN M, ROSE D., MR imaging of complications of anterior cruciate ligament graft reconstruction, Radiographics. 2009;29:2115-26.

3.KAEDING CC, PEDROZA AD, REINKE EK, et al., Change in Anterior Cruciate Ligament Graft Choice and Outcomes Over Time. Arthroscopy 2017;33:2007-14

4.HOHER J, LIVESAY GA, MA CB, et al., Hamstring graft motion in the femoral bone-tunnel when using titanium button/polyether tape fixation, Knee Surg Sports Traumatol Arthrosc. 1999;7: 215-9.

5.CLARK R, OLSEN RE, LARSON BJ, GOBLE EM, FARRER RP., Cross-pin femoral fixation: A new technique for hamstring anterior cruciate ligament reconstruction of the knee. Arthroscopy 1998;14:258-67

6.AHMAD CS, GARDNER TR, GROH M, ARNOUK J, LEVINE WN., Mechanical properties of soft tissue femoral fixation devices for anterior cruciate ligament reconstruction, AmJ Sports Med 2004;32:635-40.

7.HARVEY A, THOMAS NP, AMIS AA., Fixation of the graft in reconstruction of the anterior cruciate ligament., J Bone Joint Surg Br 2005;87:593-603.

8.MILANO G, MULAS PD, ZIRANU F, et al., Comparison between different femoral fixation devices for ACL reconstruction with doubled hamstring tendon graft: A biomechanical analysis. Arthroscopy 2006;22:660-8.

9.SCHEFFLER SU, SÜDKAMP NP, GÖCKENJAN A, HOFFMANN RF, WEILER A., Biomechanical comparison of hamstring and patellar tendon graft anterior cruciate ligament reconstruction techniques: The impact of fixation level and fixation method under cyclic loading. Arthroscopy, 2002;28:304-15.

10.WU JL, YEH TT, SHEN HC, CHENG CK, LEE CH., Mechanical comparison of biodegradable femoral fixation devices for hamstring tendon graft--a biomechanical study in a porcine model. Clin Biomech 2009; 24:435-40. 
11.BRAND JC JR, PIENKOWSKI D, STEENLAGE E, HAMILTON D, JOHNSON DL, CABORN DN., Interference screw fixation strength of a quadrupled hamstring tendon graft is directly related to bone mineral density and insertion torque, Am J Sports Med. 2000;28(5):705-710

12.NINOMIYA T, TACHIBANA Y, MIYAJIMA T, YAMAZAKI K, ODA H., Fixation strength of the interference screw in the femoral tunnel: The effect of screw divergence on the coronal plane. Knee. 2011;18(2): 83-87.

13.BROWN CH JR, WILSON DR, HECKER AT, FERRAGAMO M. Graft-bone motion and tensile properties of hamstring and patellar tendon anterior cruciate ligament femoral graft fixation under cyclic loading. Arthroscopy. 2004;20(9):922-935.

14.WILSON TC, KANTARAS A, ATAY A, JOHNSON DL. Tunnel enlargement after anterior cruciate ligament surgery. Am J Sports Med 2004;32(2):543-549

15.ZANTOP T, PETERSEN W., Stage-adapted treatment of infection after reconstruction of the anterior cruciate ligament, Oper OrthopTraumatol, 2011;23(4):337-350

16.FOLDAGER C, JAKOBSEN BW, LUND B, CHRISTIANSEN SE, KASHI L, MIKKELSEN LR, LIND M., Tibial tunnel widening after bioresorbable poly-lactide calcium carbonate interference screw usage in ACL reconstruction. Knee Surg Sports Traumatol Arthrosc 2010;18(1):79-84

17.SCHEFFLER SU, SÜDKAMP NP, GÖCKENJAN A, HOFFMANN RF, WEILER A., Biomechanical comparison of hamstring and patellar tendon graft anterior cruciate ligament reconstruction techniques: The impact of fixation level and fixation method under cyclic loading. Arthroscopy 2002;18:304-315.

18.FU FH, BENNETT CH, MA CB, MENETREY J, LATTERMANN C. Current trends in anterior cruciate ligament reconstruction. Part II. Operative procedures and clinical correlations. Am J Sports Med 2000;28:124-130.

19.HWANG MD, PIEFER JW, LUBOWITZ JH., Anterior cruciate ligament tibial footprint anatomy: systematic review of the 21st century literature. Arthroscopy 2012;28:728-734.

20.LUBOWITZ JH, AKHAVAN S, WATERMAN BR, AALAMI-HARANDI A, KONICEK J., Technique for creating the anterior cruciate ligament femoral socket: optimizing femoral footprint anatomic restoration using outside-in drilling. Arthroscopy 2013;29:522-528.

21.PIEFER JW, PFLUGNER TR, HWANG MD, LUBOWITZ JH., Anterior cruciate ligament femoral footprint anatomy: systematic review of the 21st century literature. Arthroscopy 2012;28:872-881.

22.SIEBOLD R, ELLERT T, METZ S, METZ J., Tibial insertions of the anteromedial and posterolateral bundles of the anterior cruciate ligament: morphometry, arthroscopic landmarks, and orientation model for bone tunnel placement. Arthroscopy 2008;24:154-161.

23.SIEBOLD R, ELLERT T, METZ S, METZ J., Femoral insertions of the anteromedial and posterolateral bundles of the anterior cruciate ligament: morphometry and arthroscopic orientation models for double-bundle bone tunnel placement--a cadaver study. Arthroscopy 2008;24:585-592.

24.LUBOWITZ JH, POEHLING GG., Watch your footprint: anatomic ACL reconstruction. Arthroscopy 2009;25:1059-1060.

25.RAMSINGH V, PRASAD N, LEWIS M., Pre-tibial reaction to biointerference screw in anterior cruciate ligament reconstruction. The Knee. 2014;21:91-94.

26.ILAHI OA, YOUNAS SA, SAHNI IK., Pretibial cyst formation after arthroscopic anterior cruciate ligament reconstruction. Arthroscopy. 2003;19:E5.

27.SANDERS TG, TALL MA, MULLOY JP, LEIS HT., Fluid collections in the osseous tunnel during the first year after anterior cruciate ligament repair using an autologous hamstring graft: natural history and clinical correlation. J. Comput Assist Tomogr. 2002;26:617-21.

28.TRAMBITAS, C., POP, TS., TRAMBITAS MIRON, A.D., DOROBANTU,D.C., BRINZNIUC, K., S53P4 Bioactive Glass-an Alternative Treatment of Bone Defects, Rev. Chim., 68, (2), 2017, 387 29.POP, T.S., POP, A., M., TRAMBITAS MIRON, A., D., BRINZANIUC, K., GURZU, S., TRAMBITAS, C., In vivo Evaluation of a Collagen Scaffold Preconditioned with Adipose-derived Mesenchymal Stem Cells Used for Bone Regeneration, Mater. Plast., 55, (4), 2018, 691 
30.HALMACIU, I., SUCIU, BA., FODOR, D., GODJA, D., TRAMBITAS, C.,VUNVULEA, V., BRINZANIUC, K., MOLNAR, C., Comparative Study on the Need for Postoperative Analgesic Medication After Surgical Treatment of Inguinal Hernia with Surgical Mesh through Laparoscopic or Classic Approach, Mat. Plast., 55, (2), 2018, 207-210

31.MIRON A.D, GENSEL J., VILLANOVA-OLIVER M., MARTIN H., Towards the geo-spatial querying of the semantic Web with ONTOAST, Web And Wireless Geographical Information Systems, 2007, Book Series: Lecture Notes in Computer Science, Vol. 4857, pp. 121-136.

32.C. TRAMBITAS, A. M. POP, A. D. TRAMBITAS MIRON, D.C. DOROBANTU, F.TABARAN, B.CORDOS, B.A. SUCIU, K. BRANZANIUC, Regeneration of Bone Defects Using Bioactive Glass Combined with Adipose-derived Mesenchymal Stem Cells - An experimental in vivo study., Rev. Chim., 70, (6), 2019, p. 1983

Manuscript received: 4.12 .2019 